This document was prepared in conjunction with work accomplished under Contract No. DE-AC09-96SR18500 with the U. S. Department of Energy.

\title{
DISCLAIMER
}

This report was prepared as an account of work sponsored by an agency of the United States Government. Neither the United States Government nor any agency thereof, nor any of their employees, nor any of their contractors, subcontractors or their employees, makes any warranty, express or implied, or assumes any legal liability or responsibility for the accuracy, completeness, or any third party's use or the results of such use of any information, apparatus, product, or process disclosed, or represents that its use would not infringe privately owned rights. Reference herein to any specific commercial product, process, or service by trade name, trademark, manufacturer, or otherwise, does not necessarily constitute or imply its endorsement, recommendation, or favoring by the United States Government or any agency thereof or its contractors or subcontractors. The views and opinions of authors expressed herein do not necessarily state or reflect those of the United States Government or any agency thereof. 


\section{Justification for Onsite Transfer of Type B Packages after Extended Storage}

\author{
T. Kurt Houghtaling \\ Washington Savannah River Company \\ Aiken, South Carolina 29808 \\ (803) 725-3360, kurt.houghtaling@srnl.doe.gov
}

\author{
T. Eric Skidmore \\ Washington Savannah River Company \\ Aiken, South Carolina 29808 \\ (803) 725-2236, eric.skidmore@srnl.doe.gov
}

\section{ABSTRACT}

This paper offers a practical means of qualifying previously loaded Type B packages for transportation onsite within the DOE complex after years of protected storage, while supporting the DOE program to maintain radworker dose as low as reasonable achievable (ALARA). Specifically, the paper discusses relevant packaging components and introduces part of a surveillance program carried out at the Savannah River Site supporting long-term storage of 3013processed plutonium-bearing materials within closed 9975 packages and its application to DOE's Equivalent Safety. Under normal service, maintenance is carried out annually to re-qualify the 9975 packagings for leak-tight transportation service. While in storage, however, annual maintenance was judged not to provide a significant increase in safety but to increase storage operation costs and to violate ALARA principles. Hence, a surveillance program was developed to investigate and confirm predictions of storage-related behavior of 9975 packaging materials, including the performance of O-ring seals and Celotex ${ }^{\circledR}$ insulation. The combination of analytical evaluations with surveillance data is shown sufficient to ensure that the 9975 packages can accommodate 1) time at storage temperature and 2) cumulative radiation dose without compromising subsequent performance under regulatory Normal Conditions of Transport or site-specific credible accident conditions.

\section{BACKGROUND}

In the coming decade, new plutonium disposition facilities are slated to begin construction at the Savannah River Site (SRS) under a Record of Decision issued by the Department of Energy (DOE) in 2000. However, until the new facilities are operational, interim storage is necessary. The DOE determined that roughly a billion taxpayer dollars could be saved if other sites around the DOE complex could ship their excess plutonium inventories to SRS for interim storage. The K-Area Material Storage (KAMS) facility meets the need for an interim repository. KAMS is a cost-effective adaptation of a building structure that has provided decades of protection and security for the SRS K-reactor (shut down permanently in
1992). Further, a portion of the building has been modified to enhance its protection systems and is now authorized to receive shipments of 9975 packages containing "3013processed" plutonium meeting the 50-year storage requirements of DOE-STD-3013-2004. ${ }^{[1]}$ A significant portion of the KAMS safety basis is credit for the robust character of the certified 9975 packaging design.

Plutonium stocks continue to be consolidated within the DOE complex, including recent de-inventory of the Rocky Flats Environmental Technology Site (RFETS), and thousands of loaded 9975 transportation packages have been received into KAMS.

\section{THE CHALLENGE}

In accordance with DOE-STD-3013-2004 and with the KAMS safety basis, a program was established for surveillance of 3013 vessels and the integrity of the 9975 packagings. $^{[2]}$ The program requires access to the package interiors. However, the KAMS facility is neither authorized nor equipped to open 9975s. Hence, the 9975 packages must be transferred onsite to a separate facility for execution of surveillance actions.

The safety basis for onsite transfer of 9975 packages at the SRS is simply the 9975 Safety Analysis Report for Packaging $^{[3]}$ (SARP), the technical safety basis for the package's certificate of compliance. The SARP requires "annual" re-qualification of the package containment vessels' for leaktight performance. Once a package's containment qualification has expired, a "Catch 22" dilemma arises. The package must be transferred to a separate location to be leakrate tested, but must be opened and favorably leak-rate tested prior to transfer.

\footnotetext{
1 The packaging must be qualified by testing within twelve months of shipment to demonstrate leaktight containment in accordance with applicable portions of ANSI Standard $\mathrm{N}-14.5$.
} 
Assuming that the leaktightness qualification of every package in KAMS can be renewed annually, "Catch 22" can be avoided. However, this benefit would require continual management and shuffling of thousands of $9975 \mathrm{~s}$ within the three-dimensional array of packages stacked several-high. In addition, the resulting condition of continual radworker proximity to the hazard would conflict with SRS policy of keeping radworker dose As Low As Reasonably Achievable (ALARA). Further, recurrent leak-rate testing would mean recurring radworker dose associated with removal of the radioactive payload from the package to provide leak-test personnel with access to the containment vessels and test apparatus. Even less desirable, the leak-rate tests could be implemented with the payload still housed within the inner containment vessel while the leak-test operator(s) absorbs dose and risks contamination of both his person and his equipment. At best, circumvention of "Catch 22" means violation of ALARA principles.

The SRS solution to this dilemma follows.

\section{THE 9975 PACKAGING}

Designed and certified for offsite shipments of plutonium bearing materials (including those from the RFETS), the 9975 packaging is thereby acceptable for onsite transportation service at the SRS. From inside outward, the key 9975 packaging components are the following.

- 304L stainless steel primary containment vessel (PCV)

- 304L stainless steel secondary containment vessel (SCV)

- $1 / 2$ inch nominal lead shielding thickness

- 5 inches nominal Celotex insulation thickness

- Stainless-steel 35-gallon drum with bolted-flange closure

These packaging components are shown in Figure 1 and discussed in detail in the 9975 SARP. Note that the 9975 was designed before the recent rulemaking that removed the federal requirement for double containment (nested containment vessels) of dispersible forms of plutonium.

The SRS surveillance program is implemented to identify any significant degradation in the safety performance of the 3013 vessels or 9975 packagings. The program requires onsite transfer (round trip) of roughly 100 packages annually from KAMS to a separate facility for non-destructive examinations. In addition, a small fraction of the items will be examined destructively. Data acquired characterizes material behaviors and will be used to establish trends for storage-driven changes in either 3013 or 9975 safety.

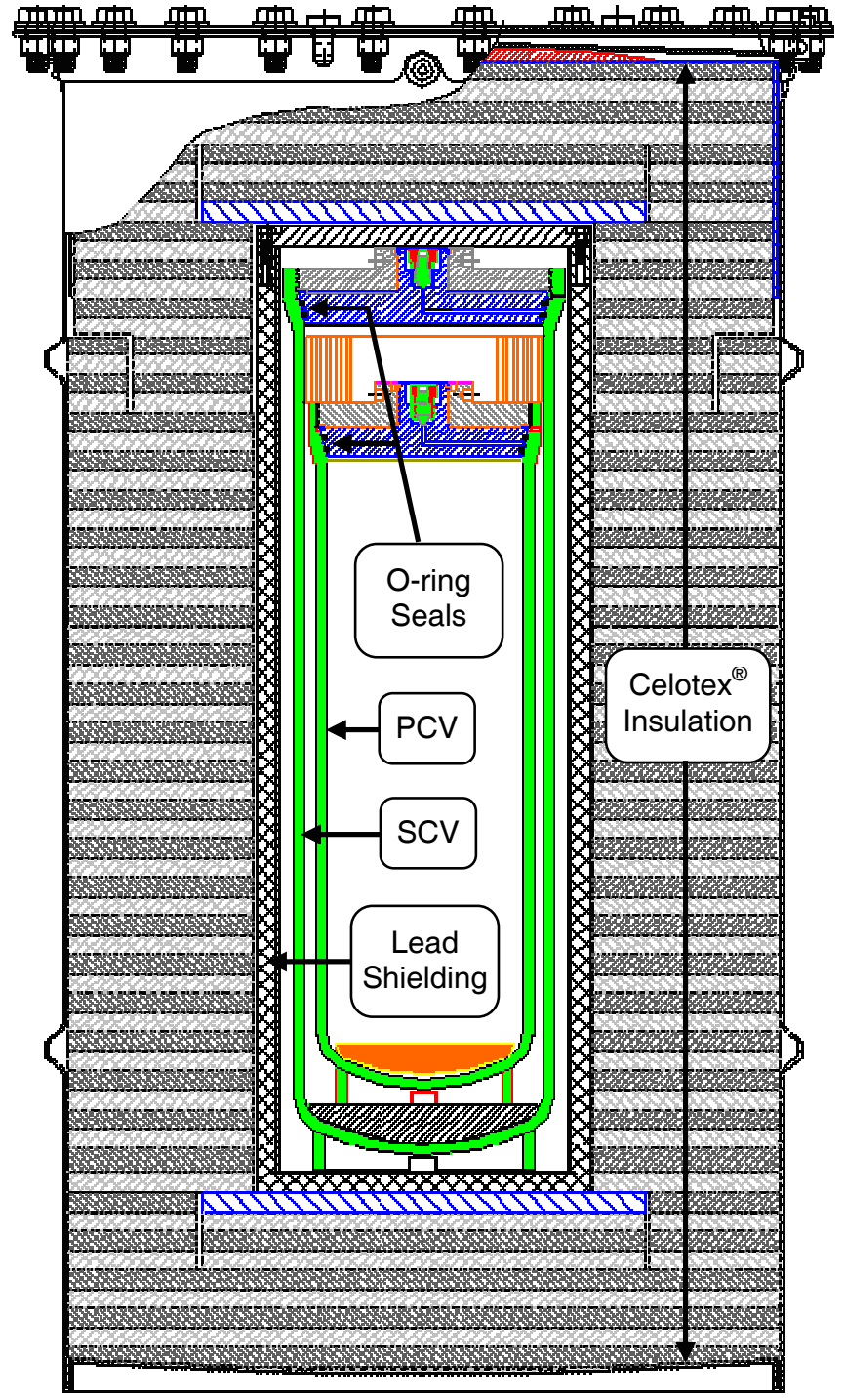

Figure 1 - Cross Sectional View of the 9975 Package

The 9975 is a robust, state-of-the-art, certified packaging designed for transportation service wherein closure seals are not maintained for more than one year. It was not designed for long-term storage service, hence, the need for surveillance of the 9975 hardware is apparent.

\section{STORAGE-RELATED ISSUES}

Loaded packages residing in protected storage provide a relatively stable environment under which organic materials can degrade. Organic materials inside the 9975 packaging include Celotex insulation, also known as cane fiberboard, and elastomeric O-rings that seal the containment vessel closures, see encircled callouts given in Figure 1. 


\section{Celotex Insulation}

The primary functions of the 9975 Celotex insulation are to provide structural and thermal protection for the package contents against the extremes of regulatory Hypothetical Accident Conditions (HAC). This behavior has been studied and evaluated under the regulatory extremes of environmental conditions and is documented in the 9975 SARP. The SARP does not require annual maintenance for the Celotex insulation.

Hence, undetected degradation of Celotex while loaded 9975s are held in the KAMS storage environment is a possibility. Recognizing that the SRS is a restricted public access area, also recognize that the credibility threshold (event probability of $1 \times 10^{-6} /$ year) for an onsite transfer accident at the SRS that could breach the containment of a certified Type B package corresponds to tens of thousands of package-miles per year. ${ }^{[4]}$ Hence, a deterministic evaluation of HAC is not necessary, and the probabilistic evaluation is sufficient to characterize the safety of normal onsite transfers of RAM in the 9975. However, given that storage-related degradation of the 9975's Celotex insulation was not considered, such undetected phenomena could adversely affect the structural performance of the package and compromise its Type B qualification. Therefore, special onsite safety requirements have been implemented as described in Section VII, Onsite Transfer Restrictions, to ensure that any undetected degradation of the 9975 package insulation is not relevant to transfer safety. Finally, the stability of 9975 Celotex properties after longterm loaded-package storage are under ongoing investigation as part of the SRS surveillance program.

\section{Elastomer Seals}

The 9975 O-ring seal material is Parker Seals fluoroelastomer compound V0835-75. Consistent with other fluoroelastomers, this compound has excellent resistance to elevated temperature degradation., The compound, typically based on Viton ${ }^{\circledR}$ GLT (DuPont Performance Elastomers), was specifically developed to improve low-temperature flexibility. The GLT designation signifies peroxide cure (G) and low temperature (LT) service, down to $-40^{\circ} \mathrm{C}$.

After delivery into KAMS, diurnal insolation (sunshine) is absent, and temperatures within the package will stabilize at levels significantly below those of regulatory Normal Condition of Transport reported in the 9975 SARP. However, radiation dose within the O-rings will continue to accumulate, eventually affecting the physical properties and performance of the O-ring material; increasing compression set and stressrelaxation. At some point, the ability of the O-rings to pass leak-rate criteria or to seal against pressure may be compromised. Storage-related issues associated with the O-ring seals are evaluated in the following sections.

\section{TEMPERATURE-INDUCED DEGRADATION}

The range of temperature through which the vendor claims satisfactory sealing performance for GLT fluoroelastomer O-rings extends as low as $-40^{\circ} \mathrm{F}$ and as high as $400^{\circ} \mathrm{F}$. These claims have been tested and confirmed within the context of the regulatory requirements for transportation, as documented in the 9975 SARP. However, in a protected storage environment such as KAMS, temperatures within the package will be significantly lower than those associated with regulatory Normal Conditions of Transport (NCT). The ambient temperature in the KAMS facility was measured for over a year and less than $0.05 \%$ of the readings briefly bumped $100^{\circ} \mathrm{F}$. Note that the thermal insulation properties of Celotex retard heat flow and thereby provide a more stable thermal environment for the containment vessels than regulatory NCT. Assuming a $100^{\circ} \mathrm{F}$ ambient environment and the maximum allowed decay heat of 19 watts from the package contents, the maximum temperature of the PCV O-rings was calculated to be $181^{\circ} \mathrm{F}$ (food-pack can payload configuration). ${ }^{[5]} \quad$ However, for the 3013 payload configuration, the maximum temperatures of the $\mathrm{PCV}$ and SCV O-rings are lower at $167^{\circ} \mathrm{F}$ and $156^{\circ} \mathrm{F}$, respectively. ${ }^{[6]}$

Since the fluoroelastomer material is resistant to much higher temperatures, the local thermal environment alone is not expected to be severe enough to cause significant degradation of the O-rings. Typically, oxidation is the dominant mode of degradation for polymers; however the potential for oxidation of the 9975 O-rings is minimal. Each groove in the cone-seal plug that holds an O-ring is designed to be nearly the same volume as the O-ring. When the containment vessels are closed, the O-rings are pushed entirely into their grooves, taking on the trapezoidal cross-section of the available volume. This condition leaves very little O-ring surface exposed to the atmosphere, and where exposure is possible, the pre-installation coating of vacuum grease will extrude into these regions and protect the surface from the limited local atmosphere. In addition, the highly fluorinated O-ring material is inherently resistant to oxidation. Hence, degradation of O-ring properties by oxidation of the fluoroelastomer material at the temperature of the SCV closure is expected to be insignificant.

This expected behavior is being tested and verified as part of the SRS surveillance program in the following manner. After accumulation of a specified gamma dose, special test fixtures simulating the PCV closure are heated and held at specific temperatures. The test temperatures correspond to the very conservative safety basis values of peak O-ring temperature associated with normal diurnal variation within KAMS or the maximum allowable continuous O-ring temperature permitted by the facility safety basis. These values are $200^{\circ} \mathrm{F}$ and $300^{\circ} \mathrm{F}$, respectively. At six month intervals, the fixtures are allowed to cool and leak-tightness is tested in accordance with ANSI N-14.5. ${ }^{[7]}$ 


\section{RADIATION-INDUCED DEGRADATION}

Viton type fluoroelastomers are generically resistant to the influence of radiation as described below.

“...Viton... can withstand $10^{5}-10^{6}$ rads with little or no measurable effect on physical properties and $10^{7}$ rads with moderate effect such as $50 \%$ loss of elongation and $50 \%$ increase in modulus." ${ }^{[8]}$

O-ring dose rates are developed conservatively as follows. The plutonium/uranium metal and 3013-processed oxide contents received into the KAMS facility are benign compared to the RFETS Sand, Slag and Crucible (SS\&C) residue materials evaluated previously for (but not approved) shipment in the 9975 package. The SS\&C materials include $(\alpha, n)$-reactive fluoride compounds and because of this, dose rates associated with the SS\&C are significantly higher than those from the metal and 3013 oxide. The SS\&C dose rates calculated at the O-ring locations within the PCV and SCV are 2.0 and $0.04 \mathrm{R} /$ hour, respectively.

Crediting removal of the double containment requirement from 10 CFR 71.63 implemented January 1, 2005, only a single containment vessel is necessary for compliance with current federal law, and hence, SRS equivalent safety. Therefore, considering only the location of the SCV O-rings, the time required to reach the lower threshold for measurable effect on physical properties ( $10^{5}$ rads) is the following.

$$
\begin{aligned}
\mathrm{t}_{\text {dose threshhold }}= & \left(1 \times 10^{5} \mathrm{R} / 0.04 \mathrm{R} / \text { hour }\right)(1 \text { day } / 24 \text { hours }) \\
& (1 \text { year } / 365.25 \text { days })=\mathbf{2 8 5} \text { years }
\end{aligned}
$$

Based conservatively on dose rates from the RFETS SS\&C materials, loaded 9975s may remain stored in the KAMS facility for 285 years before the SCV seals accumulate sufficient dose to begin affecting their physical properties.

As part of the SRS surveillance program, test fixtures simulating a PCV closure are irradiated to a total dose of $1.75 \mathrm{E}+5$ rads. This is equivalent to a ten-year cumulative dose at the bounding dose rate expected for the PCV O-rings ( $2 \mathrm{rad} / \mathrm{hr}$ ). The irradiations are carried out at two different dose rates $\left(\sim 2 \times 10^{4}\right.$ or $\left.\sim 2 \times 10^{5} \mathrm{rad} / \mathrm{hr}\right)$ to evaluate potential dose-rate effects. The irradiated fixtures are tested for leaktightness and then subjected to elevated temperatures as cited in Section V, Temperature-Induced Degradation. Approximately 60 fixtures are currently being tested.

\footnotetext{
2 Such data are usually based on exposures at much higher dose rates than expected in service. Many studies have shown that degradation at lower dose rates is often more severe, due primarily to diffusion-limited.
}

\section{Compression Set and Compression Stress Relaxation}

Irrespective of how compression set may build into O-rings in service, some measure of this behavior is relevant in static applications such as the 9975 containment vessel closures. However, materials with severe compression set are known to maintain a seal under certain conditions. Initial qualification of the 9975 packaging for extended storage service included limited leak-rate testing of PCV closures using O-rings artificially aged to $50 \%$ and $85 \%$ (moderate and severe) compression-set values. ${ }^{[9]}$ Pressure differentials sustained by the closure included 500 and 750 psig. In all cases, the O-rings with $50 \%$ and $85 \%$ compression set tested leaktight (leak rate less than $2 \times 10^{-7}$ reference cc/sec helium) against the 500-psig pressure gradient. Only at the higher test pressure of 750 psig did the closure seal leak just enough to miss qualifying as leaktight.

Therefore, even O-rings exhibiting high compression-set $(85 \%)$ are expected to maintain leak-tight seals in the 9975 $\mathrm{CV}$ designs at internal pressures of at least 500 psig. This pressure is much higher than the $\mathrm{CV}$ pressures associated with 3013-processed plutonium oxide five years after sealing within the 9975 package.

More recently, compression stress-relaxation (CSR) tests were performed on the $9975 \mathrm{CV}$ seals. ${ }^{[10]}$ CSR is a direct measure of sealing force decay, rather than a simple measure of thickness after an arbitrary period of time under compression (compression set). These tests showed that a $90 \%$ loss in sealing force is observed after approximately 500 hours at $400^{\circ} \mathrm{F}$ for O-rings with no lateral constraint and after 1000 hours for O-rings confined in a PCV O-ring groove. The point of near-zero sealing force is observed at approximately twice these values. CSR values were determined at different temperatures in an effort to develop a predictive model for seal lifetime.

A sealed PCV recently oven-aged at $400^{\circ} \mathrm{F}$ for 1500 hours also qualified as leaktight and confirmed the O-rings ability to satisfy the regulatory containment requirement even at very low values of sealing force. Additional tests are planned to determine the relationship between sealing force decay and leak rate.

Gas generation within the 3013 vessel is credible only from radioactive decay of plutonium $\left(19\right.$ watts of $\left.{ }^{239} \mathrm{Pu}\right)$ and from radiolysis of adsorbed moisture. Helium generation from radioactive decay is a slow process, and ten years of accumulation (25.2 micro-moles) amounts to less than one per cent of the hydrogen liberated by radiolysis of the moisture content (25 grams) permitted by the standard. ${ }^{[11]}$ Accepting the standard's assertion that 3013-processed materials exhibit no-net-oxygen-gas generation, only hydrogen is added to the local atmosphere as moisture is radiolyzed. Conservatively, all 25 grams of water are assumed to radiolyze completely and 
instantaneously after closing the PCV. Hydrogen generated by this hypothetical event is added to the gases already present, and under storage conditions the combination results in pressures of about 225 psig in the PCV and much less in the SCV. ${ }^{3}{ }^{[6]}$ These pressures under storage conditions (no solar heating) are significantly less than the Maximum Normal Operating Pressures (MNOPs) documented in the SARP for the containment vessels under NCT (with regulatory solar heating). Note that if the welded closure of the 3013 vessel does not leak, pressures within the PCV and SCV will be less than five psig.

\section{O-ring Seal Degradation Summary}

The core question is how much 9975-storage time is required before the containment vessel O-rings degrade (defined by compression set, stress-relaxation, etc.) to the point where ANSI-standard leak-rate ${ }^{4}$ behavior is no longer acceptable or where sealing performance becomes questionable.

Under the environmental conditions expected within KAMS, the nature of fluoroelastomer seals is to perform well for an extended period of time. However, at some point, a damage threshold may be reached due to diffusion-limited oxidation effects, exacerbated by long-term exposure to elevated temperature and low dose-rate radiation. This type of behavior has been observed in other elastomer materials in other studies. However, the time required to reach this threshold is unknown and dependent upon many factors.

Data that will help answer the threshold question is coming from ongoing surveillance of KAMS-stored 9975 packages and from the test program. Hence, authorization for onsite transfer of KAMS-stored 9975s and subsequent results from testing of O-ring seal properties/performance in support of onsite-transfer safety will have to "leap-frog" one another. Stated another way, reasonable extrapolation of existing package-transfer safety specifically for pursuit of confirmation of the validity of the extrapolation is also reasonable.

Some initial data from the long-term O-ring testing portion of the SRS surveillance program has been compiled, and the results are $100 \%$ favorable. ${ }^{[12]}$

\footnotetext{
3 All inner containers are assumed to leak freely into the surrounding containment vessel. Pressure approximation was scaled linearly from NCT analysis results by reducing the average $\mathrm{PCV}$ gas temperature $93^{\circ} \mathrm{F}$ in accordance with the absence of insolation within the KAMS facility.

4 ANSI N-14.5 leak-rate testing is carried out at room temperature and under essentially one atmosphere pressure differential.
}

\section{ONSITE TRANSFER RESTRICTIONS}

First, the 9975 may be used onsite at the SRS under the same set of permissions and restrictions imposed on the package and payload by the currently approved 9975 SARP.

Authorization for onsite transfer of 9975 packages stored within the KAMS facility would be a straight forward process based on the 9975 SARP except for the following. While in storage, the annual maintenance qualification for every 9975 (including leak-rate testing of the containment vessels) will have expired. That is, the time elapsed since the containment vessels were qualified for service by the annual leak-test process is greater than two years. ${ }^{5[5,13]}$ For offsite service, the packagings would have to undergo this annual maintenance prior to shipment. However, for onsite transfer at the SRS, the site's Transportation Safety Document (TSD) implements DOE Order 460.1B, and permits application of equivalent safety to the transfer campaign.

Safety equivalence is established in part by invoking transfer restrictions established previously to render an onsite transfer accident that could breach containment as non-credible $\left(<10^{-6}\right.$ events/year). These restrictions are given below and eliminate the need to evaluate the performance of KAMS storage-aged Celotex in structural and fire accidents.

$>$ Transfer shall not take place during daily rush-hour times (6am to $8 \mathrm{am}$ and $4 \mathrm{pm}$ to $6 \mathrm{pm}$ ).

$>$ Transfer shall take place only during "acceptable weather" defined as the absence of active National Weather Service Watches or Warnings.

$>$ One escort vehicle shall lead the transfer conveyance.

$>$ Transfer conveyance shall operate with headlights on, and speed shall not exceed $45 \mathrm{mph}$.

In addition, the SARP requirement for annual maintenance, is relaxed for onsite transfer but only in support of and in conjunction with the SRS surveillance program.

\footnotetext{
5 A 9975 packaging may have undergone leak-rate testing up to one year before being loaded and sealed for transportation that can last up to one year. Hence, consistent with SARP requirements, O-ring seals may remain in service for up to two years.
} 
- KAMS-stored 9975 packages loaded and sealed for up to five years need not undergo annual maintenance including helium leak-rate testing of the containment vessels in accordance with SARP requirements (necessary for offsite shipment).

$>$ KAMS-stored 9975 packages loaded with 3013processed materials and sealed beyond five years need not undergo annual maintenance, if and only if, results from the SRS surveillance program supports projection of satisfactory seal performance for at least one year beyond the time of transfer.

\section{CONCLUSIONS}

Subject to the operational requirements given in Section VII Onsite Transfer Restrictions (requirements are indicated by the " $>$ " symbol), post-storage transfer of KAMS-stored 9975 packages complies with the SRS TSD requirement for equivalent safety assuming the following conditions.

- 9975 package payloads are plutonium- and uraniumbearing materials processed and canned for 50-year storage in accordance with DOE's 3013 standard.

- No credit was taken for the seal-welded 3013 container (700 psig design pressure) nor for the PCV (900 psig design pressure). Hence, these otherwise un-credited features of a loaded 9975 package constitute measures of defense in depth supporting the safety of the proposed onsite transfer campaign.

$>$ Data from the surveillance of 9975 package components following package storage within the KAMS facility MUST be evaluated at least annually. The results must be favorable, confirm documented expectations and support the safety of next year's onsite transfers.

Data obtained from the ongoing SRS surveillance program has been reported and interpreted in the 2005 issue of this journal, and future publications can be expected as the program continues.

The justification process described in this paper is not suggested as a rigid course of action, but as an example of how the SRS combined available information with a surveillance program to reach a goal cost-effectively. Other sites within the DOE complex that may benefit from extended storage of radioactive materials prior to onsite transfer may be able to adapt the process to site-specific needs. For example, though the 9975 packaging serves this storage mission very well, other Type B packagings could be substituted, including other elastomer seals and other packaging insulation materials.

\section{REFERENCES}

[1] Stabilization, Packaging, and Storage of PlutoniumBearing Materials, DOE Standard, DOE-STD-30132000, U.S. Department of Energy, Washington, DC 20585, 2004

[2] The Savannah River Site Surveillance Program for the Storage of Plutonium Packages in KAMS, WSRC-TR2001-00286, Revision 2, November 2004

[3] Safety Analysis Report for Packaging - Model 9975 (U), WSRC-SA-2002-00008, Revision 0, December 2003

[4] D.R. Leduc, Frequency of Container Breach During Transfer of Type B Radioactive Material in a Type B Package from F-Area to H-Area Using Onsite Data, SCLC-H-00853, Revision 0, April 16, 2001

[5] P.S. Blanton, Request for Extension to Annual Maintenance Requirement for 9975 Type B Packagings, SRT-RMPT-2002-00009, March 5, 2002

[6] N.K. Gupta, Thermal Analysis of the 9975 Package for Normal Conditions of Transport and Hypothetical Accident Conditions, M-CLC-F-00590, Rev. 8, October 28, 2003

[7] American National Standard for Radioactive Material Leakage Tests on Packages for Shipment, ANSI N14.5, American National Standards Institute, Inc. 1997

[8] T.E. Skidmore, Performance Evaluation of O-Ring Seals in Model 9975 Packaging Assemblies (U), WSRC-TR-9800439, Revision 0, December 1998

[9] T.E. Skidmore, Leak Testing of Artificially-Aged O-Ring Seals for Model 9975 Packaging Assemblies (U), WSRCTR-99-00041, Revision 0, February 1999

[10] T.E. Skidmore, Baseline Compression Set and StressRelaxation of Model 9975 Shipping Package O-Rings (U), WSRC-TR-2004-00331, December 2004

[11] S.J. Hensel, Determination of Pressures in the 9975 Package for Impure Pu Oxide Contents, M-CLC-F00630, Revision 0, January 17, 2000

[12] K. Marshall and T.E. Skidmore, Interim Status Report: Model 9975 PCV O-ring Long-Term Leak Performance(U), WSRC-TR-2005-00015, Revision 0, July 2005

[13] J.H Roberson Memorandum to B.A. Mazurowski, Rocky Flats Field Office and G.P. Rudy, Savannah River Operations Office, Approval of Annual Maintenance Extension for 156 Loaded 9975 Packages, Docket 02-8-9975, DOE Environmental Management, May 15, 2002 